\title{
ACERVO JOÃO BATISTA VILANOVA ARTIGAS
}

Esta é a relação das obras do arquiteto João Batista Vilanova Artigas, constantes no arquivo de originais da Biblioteca da FAUUSP.

Resultado de transferência de acervo da Fundação Vilanova Artigas, esses documentos foram recuperados, quanto a rasuras, manchas, etc., e preservados dentros de cápsulas estanques de poliéster (mylar) pelo setor de Preservação do Acervo, com o trabalho das bibliotecárias: Lisely S. de Carvalho Pinto, Maria Satiko Matsuoka e a técnica Rita de Cássia Camargo. Foram classificados pelas bibliotecárias: Neusa Kazue Habe e Rosilene Lefone, e a técnica Maria Iracema Ferreira. Ambos os setores coordenados pela diretora da Biblioteca da FAUUSP, Eliana de Azevedo Marques, que se responsabilizou pelo projeto junto da VITAE.

\section{Júlio Roberto Katinsky}

Professor titular do Departamento de História da Arquitetura e Estética do Projeto, professor orientador do curso de pós-graduação e ex-diretor da FAUUSP. 


\begin{tabular}{|c|c|c|c|}
\hline Classificação & Título & Local & Data \\
\hline P AR78/624.25 PP & Viaduto Paranapiacaba & Santo André-SP & 1975 \\
\hline P AR78/624.25 VB & $\begin{array}{l}\text { Viaduto da Serra de Botucatu para o DER / CEA - Departamento } \\
\text { de Estradas e Rodagem, na rodovia Presidente Castelo Branco }\end{array}$ & Botucatu-SP & 1970 \\
\hline P AR78/628.13 RT & $\begin{array}{l}\text { Reservatório de Água e Torre Elevatória para o Departamento de } \\
\text { Águas e Esgotos, em Interlagos }\end{array}$ & São Paulo-SP & 1969 \\
\hline P AR78/690.24 BR & $\begin{array}{l}\text { Livraria Brasiliense, para o sr. Caio da Silva Prado, na rua Dom } \\
\text { José de Barros, } 165 \text { - Reforma }\end{array}$ & São Paulo-SP & 1945 \\
\hline P AR78/690.24 LB & $\begin{array}{l}\text { Livraria Brasiliense, para o sr. Caio da Silva Prado, na rua Barão } \\
\text { de Itapetininga - Reforma }\end{array}$ & São Paulo-SP & 1946 \\
\hline P AR78/690.24 RA & $\begin{array}{l}\text { Reforma do apartamento do sr. Roberto Abucham, na rua } \\
\text { Albuquerque Lins, 1293, apartamento 192, Santa Cecília }\end{array}$ & São Paulo-SP & 1975 \\
\hline P AR78/711 PJ & $\begin{array}{l}\text { Passarela na rua Justino Paixão sobre a avenida Ramiro Colleoni } \\
\text { para a Prefeitura de Santo André }\end{array}$ & Santo André-SP & 1974 \\
\hline P AR78/711.17 PPB & $\begin{array}{l}\text { Plano Piloto de Brasília, para o governo federal do Brasil - } \\
\text { Concurso }\end{array}$ & Brasília-DF & 1956 \\
\hline P AR78/711.4 FRA & $\begin{array}{l}\text { Urbanização da Fazenda Rancho Alegre, de Thyrso Silva Gomes, } \\
\text { destinada à cidade de Porto Brasílio }\end{array}$ & Paranavaí-PR & 1953 \\
\hline P AR78/711.4 P & $\begin{array}{l}\text { Urbanização de praia na Estrada Geral, antiga estrada para } \\
\text { Florianópolis, para a Sociedade Camboriú de Hotéis }\end{array}$ & Camboriú-SC & 1973 \\
\hline P AR78/711.4 PJ & Urbanização da Praia de Juqueimirim & São Sebastião-SP & 1963 \\
\hline P AR78/711.52 JAU & Centro Social Urbano de Jaú & Jaú-SP & 1974 \\
\hline P AR78/711.58 A & $\begin{array}{l}\text { Cecap Americana - Projeto de Conjunto Habitacional para a } \\
\text { Companhia Estadual de Casas Populares - Cecap, na avenida } \\
\text { Paschoal Ardito com a rua São Marcos, Vila São Manuel }\end{array}$ & Americana-SP & 1972 \\
\hline P AR78/711.58 C V.1-4 & $\begin{array}{l}\text { Cecap Cumbica - Zezinho Magalhães Prado: } \\
\text { Conjunto habitacional, conjunto comercial, hospital, centro } \\
\text { comunitário e centro de saúde }\end{array}$ & Guarulhos-SP & 1967 \\
\hline P AR78/711.58 CB & $\begin{array}{l}\text { Conjunto habitacional para a Construtora Better, na avenida } \\
\text { Nicola Capucci com a avenida Pereira Campos }\end{array}$ & Jacareí-SP & 1983 \\
\hline P AR78/711.58 J V.1-6 & $\begin{array}{l}\text { Parque Cecap de Jundiaí, na Estrada Velha de Jundiaí a } \\
\text { Campinas, Sítio Santo Antonio para Cecap - Caixa Estadual de } \\
\text { Casas para o Povo }\end{array}$ & Jundiaí-SP & 1973 \\
\hline P AR78/711.58 M V.1-2 & $\begin{array}{l}\text { Parque Cecap Mogi-Guaçu - Projeto de Conjunto Habitacional } \\
\text { para a Companhia Estadual de Casas Populares - Cecap, na rua } \\
\text { Amazonas com a avenida Franco Godoy Bueno }\end{array}$ & Mogi-Guaçu-SP & 1977 \\
\hline P AR78/711.58 MA V.1-2 & $\begin{array}{l}\text { Parque Cecap Marília - Projeto de Conjunto Habitacional para a } \\
\text { Companhia Estadual de Casas Populares - Cecap, na rua } \\
\text { Antonio Abdo e rua dos Cristais }\end{array}$ & Marília-SP & 1976 \\
\hline P AR78/711.58 PCJ V1-6 & Parque Cecap Jaú - Bairro Jardim João da Velha & Jaú-SP & 1976 \\
\hline P AR78/711.59। & Aproveitamento Turístico da Costa de Itapuí, na avenida Fluvial & Itapuí-SP & 1970 \\
\hline P AR78/711.59 JAU & $\begin{array}{l}\text { Urbanização do Parque Municipal de Jaú, na margem direita do } \\
\text { rio Jaú }\end{array}$ & Jaú-SP & 1977 \\
\hline P AR78/711.59 PJ & $\begin{array}{l}\text { Reurbanização da Praça Barão do Rio Branco, nas ruas Edgard } \\
\text { Ferraz, Paissandu e Major Prado, para a Prefeitura Municipal de } \\
\text { Jaú }\end{array}$ & Jaú-SP & 1974 \\
\hline P AR78/711.59 RUM V.1-8 & Renovação urbana em Mauá & Mauá-SP & 1974 \\
\hline P AR78/711.59 VA V.1-6 & Renovação urbana do Vale do Anhangabaú & São Paulo-SP & 1973 \\
\hline P AR78/711.63 JLB & $\begin{array}{l}\text { Loteamento do Jardim Leonor de Barros, de propriedade do } \\
\text { Ipesp, no Tucuruvi }\end{array}$ & São Paulo-SP & 1975 \\
\hline
\end{tabular}




\begin{tabular}{|c|c|c|c|}
\hline Classificação & Título & Local & Data \\
\hline P AR78/711.7 AE & $\begin{array}{l}\text { Passarela na avenida Rubem Berta, em frente ao Aeroporto de } \\
\text { Congonhas, Planalto Paulista, para Empresa Municipal de } \\
\text { Urbanização - Emurb }\end{array}$ & São Paulo-SP & 1972 \\
\hline P AR78/711.7 AF & Passarela sobre a avenida Coronel Alfredo Flaquer & Santo André - Sp & 1975 \\
\hline P AR78/711.7 AR & $\begin{array}{l}\text { Passarela na avenida Rubem Berta com a avenida Aratans, } \\
\text { Planalto Paulista, para Empresa Municipal de Urbanização- } \\
\text { Emurb }\end{array}$ & São Paulo-SP & 1972 \\
\hline P AR78/711.7 BRAS & $\begin{array}{l}\text { Passarela sobre os trilhos da Estação Roosevelt da RFFSA, na } \\
\text { Praça Agente Cícero com a rua Domingos Paiva, Brás, para } \\
\text { Empresa Municipal de Urbanização - Emurb }\end{array}$ & São Paulo-SP & 1980 \\
\hline P AR78/711.7 GV & $\begin{array}{l}\text { Passarela sobre a avenida } 9 \text { de Julho com a Fundação Getúlio } \\
\text { Vargas, Bela Vista, para a Empresa Municipal de Urbanização - } \\
\text { Emurb }\end{array}$ & São Paulo-SP & 1972 \\
\hline P AR78/711.7 I & Passarela Ibirapuera, na avenida Pedro Álvares & São Paulo-SP & 1974 \\
\hline P AR78/711.7 JAU & Passarela em Jaú, sobre o rio Jaú & Jaú-SP & 1978 \\
\hline P AR78/711.7 MI & $\begin{array}{l}\text { Passarela na avenida Rubem Berta com alameda Miruna, } \\
\text { Planalto Paulista, para Empresa Municipal de Urbanização - } \\
\text { Emurb }\end{array}$ & São Paulo-SP & 1972 \\
\hline P AR78/711.7 NJ V,1 e 2 & Passarela na avenida 9 de Julho - INPS & São Paulo-SP & 1977 \\
\hline P AR78/711.7 NOJ & $\begin{array}{l}\text { Passarelas: avenida } 9 \text { de Julho, n. } 610 \text { e avenida } 9 \text { de Julho / } \\
\text { Jardim M. Lisboa }\end{array}$ & São Paulo-SP & 1973 \\
\hline P AR78/711.7 PE & $\begin{array}{l}\text { Passarela Largo Padre Péricles, sobre a avenida Francisco } \\
\text { Matarazzo, Perdizes, para a Empresa Municipal de Urbanização } \\
\text { - Emurb }\end{array}$ & São Paulo-SP & 1972 \\
\hline P AR78/711.7 PL & Passarela na Lapa, na rua John Harrison e Willian Appers & São Paulo-SP & 1973 \\
\hline P AR78/711.7 PP & $\begin{array}{l}\text { Passarela na avenida Perimetral para a Prefeitura Municipal de } \\
\text { Santo André - avenida Perimetral / Próximo avenida Guilherme, } \\
\text { Centro }\end{array}$ & Santo André-SP & 1974 \\
\hline P AR78/711.7 PPB & $\begin{array}{l}\text { Passarela na avenida Pereira Barreto, rua Caiubi, Jardim Paraíso } \\
\text { para Prefeitura Municipal de Santo André }\end{array}$ & Santo André-SP & 1978 \\
\hline P AR78/711.7 PRI & $\begin{array}{l}\text { Passarela III da rodovia dos Imigrantes, km } 18,5 \text { para o } \\
\text { Desenvolvimento Rodoviário S/A - Dersa }\end{array}$ & São Paulo-SP & 1974 \\
\hline P AR78/711.7 PRIM & $\begin{array}{l}\text { Passarela II da rodovia dos Imigrantes, km 17,5 para o } \\
\text { Desenvolvimento Rodoviário S/A - Dersa }\end{array}$ & São Paulo-SP & 1974 \\
\hline P AR78/711.7 PRIS & $\begin{array}{l}\text { Passarela I da Rodovia dos Imigrantes, km. } 13,5 \text { para o } \\
\text { Desenvolvimento Rodoviário S/A - Dersa }\end{array}$ & São Paulo-SP & 1974 \\
\hline P AR78/711.7 PS & $\begin{array}{l}\text { Passarela do Sesi para a Prefeitura de Santo André sobre } \\
\text { avenida dos Eucaliptos / rio Tamanduateí / SESI }\end{array}$ & Santo André-SP & 1974 \\
\hline P AR78/711.7 PSB V1-5 & $\begin{array}{l}\text { Passarelas do Paço Municipal de São Bernardo do Campo, na } \\
\text { avenida Brigadeiro Faria Lima e avenida Pereira Barreto }\end{array}$ & $\begin{array}{l}\text { São Bernado do Campo- } \\
\text { SP }\end{array}$ & 1975 \\
\hline P AR78/711.7 PVT & $\begin{array}{l}\text { Passarela na avenida } 23 \text { de Maio com a rua Coronel Oscar Porto, } \\
\text { no Paraíso, para a Empresa Municipal de Urbanização - Emurb }\end{array}$ & São Paulo-SP & 1972 \\
\hline P AR78/712.6 PCP & Paisagismo para a Prefeitura Municipal de Campo Limpo & São Paulo-SP & 1980 \\
\hline P AR78/725.132 CCJ & Centro Cívico de Jaú, na rua Paisandu com a rua Major Prado & Jaú-SP & \\
\hline P AR78/725.132 FP & $\begin{array}{l}\text { Fórum de Promissão, para o Instituto de Previdência do Estado } \\
\text { de São Paulo - Ipesp, nas ruas Riko Grande e Vinte e Um de } \\
\text { Abril }\end{array}$ & Promissão-SP & 1959 \\
\hline P AR78/725.132 GU & $\begin{array}{l}\text { Edifício para prestação de serviços públicos para a Companhia } \\
\text { Energética de São Paulo - Cesp, na rua Valéria Ciccone com a } \\
\text { avenida Helena Maria }\end{array}$ & Guarujá-SP & 1979 \\
\hline
\end{tabular}




\begin{tabular}{|c|c|c|c|}
\hline Classificação & Título & Local & Data \\
\hline P AR78/725.132 MF & $\begin{array}{l}\text { Edifício de escritórios e agência da Receita Federal do Ministério } \\
\text { da Fazenda, nas avenidas Duque de Caxias, Iracema Carvão } \\
\text { Nunes e rua Eliezer Levy }\end{array}$ & Macapá-AP & 1973 \\
\hline P AR78/725.132 U & $\begin{array}{l}\text { Edifício para prestação de serviços públicos para a Companhia } \\
\text { Energética de São Paulo - Cesp, na rua Amazonas com a rua } \\
\text { Acre }\end{array}$ & Ubatuba-SP & 1979 \\
\hline P AR78/725.18 QGT & $\begin{array}{l}\text { Quartel General da Guarda Territorial do Governo Federal do } \\
\text { Amapá, na rua Odilardo Silva, avenida Aimor e rua Jovino Sino }\end{array}$ & Macapá-AP & 1971 \\
\hline P AR78/725.2 AC & $\begin{array}{l}\text { Edifício Sociedade Auto Comercial Ltda. (Autolon) e Cinema Ouro } \\
\text { Verde, na rua Maranhão com a rua Minas Gerais }\end{array}$ & Londrina-PR & 1948 \\
\hline P AR78/725.2 AD & Edifício Comercial Sede da Adesite S/A., na rua Silva Jardim, s/n. & São Paulo-SP & 1961 \\
\hline P AR78/725.2 AE & $\begin{array}{l}\text { Edifício Comercial para a Equitativa dos Estados Unidos do Brasil } \\
\text { na, rua Formosa, } 367\end{array}$ & São Paulo-SP & 1945 \\
\hline P AR78/725.2 AEB & $\begin{array}{l}\text { Edifício de escritórios para a Equitativa dos Estados Unidos do } \\
\text { Brasil, na avenida Anhangabaú com a avenida Irradiação - Sede }\end{array}$ & São Paulo-SP & 1950 \\
\hline P AR78/725.2 AL V.1-3 & $\begin{array}{l}\text { Edifício comercial como sede para as Indústrias Andrade Latorre } \\
\text { S/A., na rua Barão de Jundiaí, esquina com a rua Siqueira de } \\
\text { Morais }\end{array}$ & Jundiaí-SP & 1962 \\
\hline P AR78/725.2 ALP & Conjunto de dois prédios em Alphaville, na rua Itapecuru & São Paulo-SP & 1984 \\
\hline P AR78/725.2 AP & $\begin{array}{l}\text { Edifício comercial para a Agência de Propaganda Dória } \\
\text { Associados, Edifício Cbi - L. Korngold, na rua Formosa, } 367 \text { - } \\
\text { Reforma de um pavimento }\end{array}$ & São Paulo-SP & 1951 \\
\hline P AR78/725.2 CF & $\begin{array}{l}\text { Edifício comercial "Casa Fachada", de propriedade dos srs. } \\
\text { Wolfang e Ary Fachada, na praça Patriarca, } 27 \text { - Reforma }\end{array}$ & São Paulo - Sp & 1941 \\
\hline P AR78/725.2 CO & $\begin{array}{l}\text { Edifício comercial para a Cia. União dos Refinadores, na rua } \\
\text { Borges de Figueiredo, } 237 \text { com a rua Guaratinguetá - Mooca }\end{array}$ & São Paulo - Sp & $1943 / 44$ \\
\hline P AR78/725.2 CON & $\begin{array}{l}\text { Edifício comercial para a Empresa Concialpa S/A., nos Aeroportos } \\
\text { de Congonhas e Viracopos - Reforma }\end{array}$ & São Paulo e Campinas-SP & 1973 \\
\hline P AR78/725.2 ED & $\begin{array}{l}\text { Edifício de escritórios para os srs. João Batista Vilanova Artigas, } \\
\text { Rino Levi, Icaro C. Mello e A. Paesani, na avenida Nove de Julho } \\
\text { com a rua Japão, Itaim Bibi }\end{array}$ & São Paulo-SP & 1962 \\
\hline P AR78/725.2 EDI & Editora & - & 1960 \\
\hline P AR78/725.2 FE & Salão de Beleza Femme para o sr. Antoine & São Paulo-SP & 1959 \\
\hline P AR78/725.2 IAL & $\begin{array}{l}\text { Edifício comercial para as Indústrias Andrade Latorre S/A., na via } \\
\text { Anhanguera com a rua do Retiro }\end{array}$ & Jundiaí-SP & 1962 \\
\hline P AR78/725.2 INM & $\begin{array}{l}\text { Edifício comercial para o Instituto Nacional do Mate, na rua Dom } \\
\text { José de Barros, } 65 \text { - Loja na Galeria Califórnia }\end{array}$ & São Paulo-SP & 1956 \\
\hline P AR78/725.2 JB & $\begin{array}{l}\text { Edifício de escritórios, na rua Alcides Lourenço da Rocha, } \\
\text { Brooklin Novo, de João Batista Vilanova Artigas e Marlene Yurgel }\end{array}$ & São Paulo-SP & 1977 \\
\hline P AR78/725.2 JM & $\begin{array}{l}\text { Edifício comercial para o sr. José Mestres Alijostes, na avenida } \\
\text { Brigadeiro Luís Antônio, } 478\end{array}$ & São Paulo-SP & 1946 \\
\hline P AR78/725.2 LML & $\begin{array}{l}\text { Livraria Monteiro Lobato, de propriedade da Editora Brasiliense, } \\
\text { na avenida São João, } 577\end{array}$ & São Paulo-SP & 1946 \\
\hline P AR78/725.2 MA & Escritórios para o sr. Manuel Antonio Mendes André & São Paulo-SP & 1952 \\
\hline P AR78/725.2 PEN & $\begin{array}{l}\text { Edifício comercial para a Pavan Engenharia e Indústria Ltda., na } \\
\text { rua General Furtado do Nascimento, Jaguaré }\end{array}$ & São Paulo-SP & 1972 \\
\hline P AR78/725.2 T & $\begin{array}{l}\text { Edifício comercial para a sra. Thamar Gomes de Araújo, na praça } \\
\text { General Osório s/n., Centro }\end{array}$ & Curitiba-PR & 1958 \\
\hline P AR78/725.21 GE & Loja para Geraldo D'estefani & - & - \\
\hline P AR78/725.23 BF & Escritório na rua Bento Freitas & São Paulo-SP & - \\
\hline
\end{tabular}




\begin{tabular}{|c|c|c|c|}
\hline Classificação & Título & Local & Data \\
\hline P AR78/725.23 PCE & $\begin{array}{l}\text { Escritório Distrital de Distribuição de Pirassununga da Companhia } \\
\text { Energética de São Paulo - Cesp, na rua Coronel Franco }\end{array}$ & Pirassununga-SP & 1980 \\
\hline P AR78/725.23 S & $\begin{array}{l}\text { Sanesul - Construtora e Saneamento do Sul Ltda., na rua } \\
\text { Haroldo Gurgel }\end{array}$ & São Paulo-SP & 1971 \\
\hline P AR78/725.24 BS & Agência Mooca do Banco Safra, na rua da Mooca & São Paulo-SP & 1983 \\
\hline P AR78/725.35 J & $\begin{array}{l}\text { Central de Abastecimento de Jaú - Caja, para a Prefeitura } \\
\text { Municipal de Jaú, na avenida Frederico Ozanan com a rodovia } \\
\text { Bauru-Araraquara }\end{array}$ & Jaú-SP & 1974 \\
\hline P AR78/725.35 S & Silo e armazém para o Ceagesp & Assis-SP & 1969 \\
\hline P AR78/725.384 A & $\begin{array}{l}\text { Posto de serviços para a Sociedade Auto Comercial de Londrina } \\
\text { (Autolon), na rua Sergipe com a rua Minas Gerais - Oficinas } \\
\text { Chevrolet }\end{array}$ & Londrina-PR & 1951 \\
\hline P AR78/725.384 AU & $\begin{array}{l}\text { Posto de serviços para a Sociedade Auto Comercial de Londrina } \\
\text { (Autolon), nas ruas Pará, Amazonas, Amapá e avenida Paraná - } \\
\text { Oficinas Chevrolet }\end{array}$ & Londrina-PR & 1951 \\
\hline P AR78/725.384 FL V.1-3 & $\begin{array}{l}\text { Posto de gasolina para a Petrobrás, na avenida Brigadeiro Faria } \\
\text { Lima com avenida Cidade Jardim }\end{array}$ & São Paulo-SP & 1974 \\
\hline P AR78/725.384 GF V.1-2 & $\begin{array}{l}\text { Posto de gasolina para a Petrobrás, na avenida Presidente } \\
\text { Castelo Branco com a rua General Flores, Bom Retiro }\end{array}$ & São Paulo-SP & 1974 \\
\hline P AR78/725.384 IT V.1-2 & $\begin{array}{l}\text { Posto de gasolina para a Petrobrás, na avenida Presidente } \\
\text { Castelo Branco com a rua Iturama, Pari }\end{array}$ & São Paulo-SP & 1974 \\
\hline P AR78/725.384 JM & $\begin{array}{l}\text { Posto de gasolina para o sr. José Mestres Alijostes, na avenida } \\
\text { Brigadeiro Luís Antônio, 478, Bela Vista }\end{array}$ & São Paulo-SP & 1949 \\
\hline P AR78/725.384 T & Posto Transparaná Ltda. & - & 1950 \\
\hline P AR78/725.384 TL & Posto Transparaná Ltda., na rua Nova com a avenida Paraná & Londrina-PR & 1950 \\
\hline P AR78/725.384 TM & Posto Transparaná Ltda. & Maringá-PR & 1950 \\
\hline P AR78/725.384 TP & Posto Transparaná Ltda. & Paranaguá-PR & 1950 \\
\hline P AR78/725.386 ERL & Estação Rodoviária de Londrina & Londrina-PR & 1950 \\
\hline P AR78/725.386 JAU V.1-8 & $\begin{array}{l}\text { Estação Rodoviária de Jaú, nas ruas Humaitá, Marechal } \\
\text { Bittencourt e Saldanha Marinho }\end{array}$ & Jaú-SP & 1973-1992 \\
\hline P AR78/725.386 JU & $\begin{array}{l}\text { Estação Rodoviária de Jundiaí, na avenida Marginal com a rua } \\
\text { Coronel Boaventura Mendes }\end{array}$ & Jundiaí-SP & 1968 \\
\hline P AR78/725.4 CA V.1-2 & $\begin{array}{l}\text { Indústrias Carbex Química Ltda. (Ex Asite Ltda.), na rua Antonio } \\
\text { Blasques, 23, com a rua Baião Parente, Frequesia do Ó }\end{array}$ & São Paulo-SP & 1957 \\
\hline P AR78/725.4 SD & $\begin{array}{l}\text { Perfumaria San Dar S/A. Indústria de Perfumes, na rua Teodoro } \\
\text { Sampaio, } 1422 \text {, com a rua Cônego Eugênio Leite }\end{array}$ & São Paulo-SP & 1945 \\
\hline P AR78/725.4 SM & Fábrica Sanyo Marubeni & Manaus-AM & 1972 \\
\hline P AR78/725.4 TR & $\begin{array}{l}\text { Trol S/A. Indústria e Comércio, na rua Tocantins com a rua } \\
\text { Ipiranga }\end{array}$ & São Paulo-SP & 1973 \\
\hline P AR78/725.5 AM & Pronto Socorro para o governo federal do Amapá & Macapá-Ap & 1971 \\
\hline P AR78/725.5 GA & $\begin{array}{l}\text { Clínica Médica Giocondo Vilanova Artigas e A. Antoniuk, na rua } \\
\text { Alcides Munhoz e rua Jacarezinho }\end{array}$ & Curitiba-PR & 1973 \\
\hline P AR78/725.5 HL & Hospital de Londrina, na rua São Paulo com a rua Piauí & Londrina-PR & 1948 \\
\hline P AR78/725.5 HSL V1-2 & $\begin{array}{l}\text { Hospital São Lucas, na avenida João Gualberto com a avenida } \\
\text { Graciosa }\end{array}$ & Curitiba-PR & 1945 \\
\hline P AR78/725.5 MA & Hospital Martinho & - & 1958 \\
\hline P AR78/725.5 MZ V.1-3 & $\begin{array}{l}\text { Clínica Médica e Consutório para o dr. Marcelo Zubarb, na } \\
\text { avenida Brasil esquina com a rua Veneza }\end{array}$ & São Paulo-SP & 1980 \\
\hline P AR78/725.5 POSA & Policlínica Santa Amália, na rua Herminio Lemos, 385, Cambuci & São Paulo-SP & 1976 \\
\hline
\end{tabular}




\begin{tabular}{|c|c|c|c|}
\hline Classificação & Título & Local & Data \\
\hline P AR78/725.5 PP & $\begin{array}{l}\text { Hospital Geral de Porto Primavera, de propriedade da } \\
\text { Companhia Energética de São Paulo - Cesp, no bairro Usina }\end{array}$ & Porto Primavera-SP & 1978 \\
\hline P AR78/725.5 PSA V.1-3 & $\begin{array}{l}\text { Policlínica Santa Amália, na rua Gama Cerqueira, 674, 682, } 688 \\
\text { e 702, no Cambuci }\end{array}$ & São Paulo-SP & 1976 \\
\hline P AR78/725.5 SC V.1-8 & $\begin{array}{l}\text { Hospital e Maternidade São Cristóvão, na rua Dr. Alberto } \\
\text { Benedeti com a avenida Dr. Erasmo - Construção e reforma }\end{array}$ & Santo André-SP & $1968 / 1978$ \\
\hline P AR78/725.5 SCL & Santa Casa de Londrina, na rua Alagoas com a rua Minas Gerais & Londrina-PR & 1951 \\
\hline P AR78/725.6 FE & $\begin{array}{l}\text { Pavilhão Central e Feminino da Febem, no Parque da Água } \\
\text { Funda }\end{array}$ & São Paulo-SP & 1965 \\
\hline P AR78/725.6 FEB & $\begin{array}{l}\text { Pavilhão de Triagem de Menores da Febem, no Parque da Água } \\
\text { Funda }\end{array}$ & São Paulo-SP & 1961 \\
\hline P AR78/725.8 UBE & $\begin{array}{l}\text { Edifício Cultural da União Brasileira de Escritores e Outros, na rua } \\
\text { Joaquim Gustavo com a rua Aurora }\end{array}$ & São Paulo-SP & 1958 \\
\hline P AR78/725.824 AM & $\begin{array}{l}\text { Cinema para os srs. Alfredo Masetti e João Carlos Ronca, na rua } \\
\text { Paraíso, esquina com a rua Bernardino de Campos }\end{array}$ & São Paulo-SP & 1951 \\
\hline P AR78/725.827 EL & $\begin{array}{l}\text { Estádio Municipal de Londrina para a Comissão Pró-Estádio } \\
\text { Municipal de Londrina }\end{array}$ & Londrina-PR & 1953 \\
\hline P AR78/725.827 em V.1-9 & $\begin{array}{l}\text { Estádio Cícero Pompeu de Toledo para o São Paulo Futebol } \\
\text { Clube - Estádio do Morumbi }\end{array}$ & São Paulo-SP & 1952 \\
\hline P AR78/725.827 EZ & $\begin{array}{l}\text { Estádio Esportivo "Zerão", na Estrada da Fazendinha, para o } \\
\text { governo federal do Amapá }\end{array}$ & Macapá-AP & 1972 \\
\hline P AR78/725.85 a V.1-5 & $\begin{array}{l}\text { Anhembi Tênis Clube, na rua Alexandre Herculano com a rua } \\
\text { Orobó, Alto de Pinheiros - Sede social }\end{array}$ & São Paulo-SP & 1961 \\
\hline P AR78/725.85 CAP & $\begin{array}{l}\text { Clube Atlético Paulistano, nas ruas Honduras, Colômbia e } \\
\text { Estados Unidos }\end{array}$ & São Paulo-SP & 1958 \\
\hline P AR78/725.85 CML V.1-9 & Clube de Campo Monte Líbano, na rua Siqueira Campos, 2.943 & São José do Rio Preto-SP & $1976-1980$ \\
\hline P AR78/725.85 CMLSP & $\begin{array}{l}\text { Clube de Campo Monte Líbano, na avenida República do Líbano } \\
\text { com a avenida Ibirapuera, Jardim Luzitânia }\end{array}$ & São Paulo-SP & 1974 \\
\hline P AR78/725.85 CS & $\begin{array}{l}\text { Clube de Campo Cabo Sol, para o Centro Social dos Cabos e } \\
\text { Soldados da Força Pública de São Paulo }\end{array}$ & Taboão da Serra-SP & 1964 \\
\hline P AR78/725.85 CSP V1-5 & Santa Paula late Clube - Reforma da sede social & São Paulo-SP & $1961-62$ \\
\hline P AR78/725.85 CXV V.1-3 & $\begin{array}{l}\text { Clube XV de Novembro de Jaú, na avenida Caetano Perlatti e } \\
\text { avenida 2. Perimetral }\end{array}$ & Jaú-SP & 1970 \\
\hline P AR78/725.85 G & $\begin{array}{l}\text { Clube Guaxupé - Sede, na avenida Conde Ribeiro do Vale, } 183 \text { - } \\
\text { Reforma }\end{array}$ & Guaxupé-MG & 1948 \\
\hline P AR78/725.85 GCC & Ginásio Ed Esportes do Country Clube de Londrina & Londrina-PR & 1950 \\
\hline P AR78/725.85 GSP & $\begin{array}{l}\text { Garagem para barcos - Santa Paula late Clube, na avenida } \\
\text { Presidente Kennedy, Interlagos }\end{array}$ & São Paulo-SP & 1961 \\
\hline P AR78/725.85 J V1-5 & $\begin{array}{l}\text { Ginásio Esportivo de Jaú entre as avenidas Zezinho Magalhães e } \\
\text { Caetano Perlati }\end{array}$ & Jaú-SP & 1973 \\
\hline P AR78/725.85 JAC & Jabaquara Atlético Clube, no bairro Caneleira & Santos-SP & 1962 \\
\hline P AR78/725.85 JC & $\begin{array}{l}\text { Clube de Campo para o sr. Luiz Antonio Naves Junqueira e sr. } \\
\text { Antonio Salim Curiati, em Parelheiros }\end{array}$ & São Paulo-SP & 1972 \\
\hline P AR78/725.85 P & $\begin{array}{l}\text { Clube Associação Portuguesa de Desportos, na avenida Marginal } \\
\text { com a avenida Auxiliar, Canindé }\end{array}$ & São Paulo-SP & 1962 \\
\hline P AR78/725.85 PI & $\begin{array}{l}\text { Esporte Clube Pinheiros, na avenida Tucuman e rua Iguatemi - } \\
\text { Vestiários }\end{array}$ & São Paulo-SP & 1950 \\
\hline P AR78/725.85 SP & São Paulo Futebol Clube, no Morumbi & São Paulo-SP & 1960 \\
\hline P AR78/725.85 T V.1-2 & $\begin{array}{l}\text { Tortuga Clube, para a Santa Clara Melhoramentos S/A., na } \\
\text { avenida Marginal, Praia Tartarugas }\end{array}$ & Guarujá-SP & 1963 \\
\hline
\end{tabular}




\begin{tabular}{|c|c|c|c|}
\hline Classificação & Título & Local & Data \\
\hline P AR78/725.85 VL & Vestiários para o Country Clube de Londrina & Londrina-PR & 1951 \\
\hline P AR78/725.9 ABC V1-5 & Sindicato dos Metalúrgicos do ABC - Sede, na rua João Basso, 9 & $\begin{array}{l}\text { São Bernardo do Campo- } \\
\text { SP }\end{array}$ & 1963 \\
\hline P AR78/725.9 DO & $\begin{array}{l}\text { Divisão de Obras do Governo do Amapá, na rua Procópio Rola e } \\
\text { avenida Fab - Sede }\end{array}$ & Macapá-Ap & 1970 \\
\hline P AR78/725.9 MJ & Edifício em "L", no pátio do Metrô Jabaquara & São Paulo-SP & 1979 \\
\hline P AR78/725.9 SB & $\begin{array}{l}\text { Sindicato dos Empregados em Estabelecimentos Bancários, na } \\
\text { rua Tabatinguera, 192, Liberdade }\end{array}$ & São Paulo-SP & 1981 \\
\hline P AR78/725.9 SCU & $\begin{array}{l}\text { Sindicato dos Trabalhadores em Empresas de Carris Urbanos de } \\
\text { São Paulo, na rua Barão de Iguape, } 339\end{array}$ & São Paulo-SP & 1959 \\
\hline P AR78/725.9 SF & $\begin{array}{l}\text { Sindicato dos Trabalhadores em Empresas Ferroviárias de São } \\
\text { Paulo, na rua Santa Ifigênia, } 591 \text { a } 601 \text { - Reforma da sede }\end{array}$ & São Paulo-SP & 1961 \\
\hline P AR78/725.9 SG & $\begin{array}{l}\text { Divisão de Segurança e Guardas do Governo de Amapá - Sede, } \\
\text { nas avenidas Amazonas e Padre Júlio Maria Lombaerde }\end{array}$ & Macapá-AP & 1972 \\
\hline P AR78/725.9 SMG V1-5 & $\begin{array}{l}\text { Sindicato dos Trabalhadores das Indústrias Metalúrgica, } \\
\text { Mecânica e de Materiais Elétricos de Guarulhos }\end{array}$ & Guarulhos-SP & 1969 \\
\hline P AR78/725.9 SMSP & $\begin{array}{l}\text { Sindicato dos Trabalhadores Metalúrgicos, Mecânicos e de } \\
\text { Material Elétrico de São Paulo, na avenida Barão do Rio Branco, } \\
766 \text { - Sub-sede }\end{array}$ & São Paulo-SP & 1963 \\
\hline P AR78/725.9 SP & $\begin{array}{l}\text { Sindicato dos Trabalhadores na Indústria de Panificação e } \\
\text { Confeitaria de São Paulo, na rua Major Diogo, 126, Bela Vista - } \\
\text { Reforma da sede }\end{array}$ & São Paulo-SP & 1981 \\
\hline P AR78/725.9 SPA & $\begin{array}{l}\text { Secretaria da Segurança Pública do Governo do Amapá - Sede, } \\
\text { na rua Ernestino Borges esquina com a avenida Tiradentes }\end{array}$ & Macapá-AP & 1972 \\
\hline P AR78/725.9 SPE & Sindicato dos Petroleiros & - & 1963 \\
\hline P AR78/725.9 SR V 1-2 & $\begin{array}{l}\text { Sindicato dos Condutores de Veículos, Rodoviários e Anexos de } \\
\text { São Paulo - Sede, na rua Pirapitingui, 75, Liberdade }\end{array}$ & São Paulo-SP & 1963-1971 \\
\hline P AR78/725.9 ST & $\begin{array}{l}\text { Sindicato dos Têxteis de São José dos Campos - Sede, na rua } \\
\text { Sebastião Felicio, Jardim Bela Vista }\end{array}$ & São José dos Campos-SP & 1962 \\
\hline P AR78/725.9 STSP & $\begin{array}{l}\text { Sindicato dos Trabalhadores na Indústria de Fiação e Tecelagem } \\
\text { de São Paulo, na rua Oiapoque, 80, Brás }\end{array}$ & São Paulo-SP & 1959 \\
\hline P AR78/725.9 TI & $\begin{array}{l}\text { Sindicato dos Trabalhadores nas Indústrias de Fiação e } \\
\text { Tecelagem de Itu - Sede }\end{array}$ & Itu-SP & 1961 \\
\hline P AR78/725.9 TSA & $\begin{array}{l}\text { Sindicato dos Trabalhadores nas Indústrias de Fiação e } \\
\text { Tecelagem de Santo André, Mauá e Ribeirão Pires, na rua Monte } \\
\text { Casseros, 268/270 - Salão }\end{array}$ & Santo André-SP & 1961 \\
\hline P AR78/726 CP & Casa Paroquial e Igreja para Congregação Santa Cruz, no Jaguaré & São Paulo-SP & 1944 \\
\hline P AR78/726.5 SD & Igreja e Convento São Domingos, nas ruas Caiuby e Atibaia & - & - \\
\hline P AR78/727 CM V.1-2 & $\begin{array}{l}\text { Centro Educacional para o Sindicato dos Trabalhadores, nas } \\
\text { Indústrias Metalúrgicas, Mecânicas e de Material Elétrico de } \\
\text { Santos, São Vicente, Guarujá e Cubatão - Cemetal, na avenida } \\
\text { Paraná, esquina com a avenida Gaffre E. Guinle, } 376,378,380 \text { e } \\
382\end{array}$ & Santos-SP & 1980 \\
\hline P AR78/727 JA V1-6 & Centro Educacional de Jaú - Unidade Escolar Especial & Jaú-SP & 1968 \\
\hline P AR78/727 PM V.1-4 & Centro Educacional de Paranavaí, Jardim Paranavaí & Mauá-SP & 1975 \\
\hline P AR78/727 PV V1-7 & $\begin{array}{l}\text { Centro Interescolar do Governo do Estado de Rondônia, Porto } \\
\text { Velho }\end{array}$ & Porto Velho-Ro & 1973 \\
\hline P AR78/727 VA & $\begin{array}{l}\text { Centro Integrado de Educação Pré-Primária de Vila Alpina, na rua } \\
\text { Flora com as ruas João Fernandes e Marechal Hermes }\end{array}$ & Santo André-SP & 1970 \\
\hline
\end{tabular}




\begin{tabular}{|c|c|c|c|}
\hline Classificação & Título & Local & Data \\
\hline P AR78/727.1 AC & $\begin{array}{l}\text { Escola de } 1^{2} \text { Grau Agenor de Campos, nas ruas Aimorés, } \\
\text { Bororós, São Sebastião e Coroados, para Cia. de Construções } \\
\text { Escolares do Estado de São Paulo - Conesp }\end{array}$ & Mongaguá-SP & 1976 \\
\hline P AR78/727.1 C V1-3 & $\begin{array}{l}\text { E. E. P. G. Conceiçãozinha, na rua Um - Bairro Vicente de } \\
\text { Carvalho para Conesp }\end{array}$ & Guarujá-SP & 1976 \\
\hline P AR78/727.1 CL & Escola Casa da Criança & Londrina-PR & 1950 \\
\hline P AR78/727.1 EES & $\begin{array}{l}\text { Escola de Ensino Secundário, na alameda Barão do Rio Branco, } \\
\text { pertecente ao sr. Paulo Carezzato - Reforma e ampliação }\end{array}$ & São Paulo-SP & $1937-38$ \\
\hline P AR78/727.1 EM & $\begin{array}{l}\text { Externado Meira Judita Leite Chaves de Carvalho, na rua Pe. João } \\
\text { Manoel, n. 727, Cerqueira César - Reforma e ampliação do } \\
\text { edifício }\end{array}$ & São Paulo-SP & 1941 \\
\hline P AR78/727.1 FC V.1-5 & $\begin{array}{l}\text { Escola Estadual de Primeiro Grau Jardim Flor do Campo - } \\
\text { Unidade Escolar Guarulhos - Cecap }\end{array}$ & Guarulho-SP & 1978 \\
\hline P AR78/727.1 GG & $\begin{array}{l}\text { Ginásio de Guarulhos (Eepsg) para o Ipesp, na avenida Arminda } \\
\text { de Lima R. Timóteo Penteado, Vila Progresso (Atual Escola } \\
\text { Conselheiro Crispiniano) }\end{array}$ & Guarulhos-SP & 1960 \\
\hline P AR78/727.1 GI V.1-2 & $\begin{array}{l}\text { Ginásio de Itanhaém (Escola Estadual de Primeiro Grau Jon } \\
\text { Theodorescp ), para o Ipesp, nas ruas Júlio Pires e José Mendes } \\
\text { de Araújo }\end{array}$ & Itanhaém-SP & 1959 \\
\hline P AR78/727.1 GP & $\begin{array}{l}\text { Ginásio Polivalente do Governo Federal do Amapá, na avenida } \\
\text { Fab com a rua Rio de Janeiro e avenida Procópio Rola }\end{array}$ & Macapá-AP & 1971 \\
\hline P AR78/727.1 JC V 1,1A - 2 & $\begin{array}{l}\text { Escola Estadual de Primeiro Grau Marechal Mollet, no Jardim } \\
\text { Chapadão para a Conesp, na avenida João Erbolato com a rua } \\
\text { Monte Líbano }\end{array}$ & Campinas-SP & \\
\hline P AR78/727.1 JN V.1-2 & $\begin{array}{l}\text { Escola Estadual de Primeiro Grau Joaquim Nabuco para a } \\
\text { Conesp, nas ruas Araribóia, Santa Cecília e Bela Vista }\end{array}$ & São José do Rio Preto-SP & 1976 \\
\hline P AR78/727.1 JO & $\begin{array}{l}\text { Escola Estadual de Primeiro Grau Jardim Oiti para a Cia. de } \\
\text { Construções Escolares do Estado de São Paulo - Conesp, na rua } \\
\text { Otávio Graziani }\end{array}$ & Jales-SP & 1976 \\
\hline P AR78/727.1 JP V.1-2 & $\begin{array}{l}\text { Escola Estadual de Primeiro Grau Jardim Paulista, na avenida } 16 \\
\text { com a rua Amapá e a avenida Getúlio Vargas }\end{array}$ & Fernandópolis-SP & 1976 \\
\hline P AR78/727.1 PBE & $\begin{array}{l}\text { Escola Estadual de Primeiro Grau Parque Boa Esperança, Campo } \\
\text { Limpo }\end{array}$ & São Paulo-SP & 1977 \\
\hline P AR78/727.1 PBE V.1-2 & $\begin{array}{l}\text { Escola Estadual de Primeiro Grau J. Parque Boa Esperança, no } \\
\text { Campo Limpo }\end{array}$ & São Paulo-SP & 1977 \\
\hline P AR78/727.1 PCS & $\begin{array}{l}\text { Ginásio Presidente Costa e Silva, na avenida Ana Neri com a rua } \\
\text { José Serafim, para o governo federal do Amapá }\end{array}$ & Macapá-AP & 1971 \\
\hline PAR78/727.1 PL & $\begin{array}{l}\text { Escola Estadual de Primeiro Grau Parque Ludovico - Unidade } \\
\text { Escolar com } 13 \text { e } 16 \text { salas ambiente }\end{array}$ & Carapicuíba-SP & 1977 \\
\hline P AR78/727.1 PL V.1-2 & $\begin{array}{l}\text { Escola Estadual de Primeiro Grau Parque Ludovico - Unidade } \\
\text { Escola com } 13 \text { e } 16 \text { salas ambiente }\end{array}$ & Carapicuíba-SP & 1977 \\
\hline P AR78/727.1 SP V.1-4 & $\begin{array}{l}\text { Escola Estadual de Primeiro Grau Sete Praias, na Estrada do } \\
\text { Jataí, Santo Amaro, para a Conesp }\end{array}$ & São Paulo-SP & 1976 \\
\hline P AR78/727.1 UT V.1-5 & $\begin{array}{l}\text { Ginásio Estadual de Utinga - Escola Estadual de Primeiro Grau } \\
\text { na } 31 \text { de Março para o Ipesp, Avenida Utinga, 1100, Utinga }\end{array}$ & Santo André-SP & 1962 \\
\hline P AR78/727.1 VM & $\begin{array}{l}\text { Escola Estadual de Primeiro Grau Vila Menck, Unidade Escolar } \\
\text { com } 14 \text { salas ambiente }\end{array}$ & Carapicuíba-SP & 1979 \\
\hline P AR78/727.2 CD V.1-4 & $\begin{array}{l}\text { Colégio Doze de Outubro, para os srs. Remo Rinaldi Naddeo e } \\
\text { Mário Naddeo, na rua Comendador Elias Zarzur, 301, Santo } \\
\text { Amaro }\end{array}$ & São Paulo-SP & 1962 \\
\hline P AR78/727.3 BIE & $\begin{array}{l}\text { Faculdade de Arquitetura e Urbanismo - Biblioteca - Instalações } \\
\text { elétricas }\end{array}$ & São Paulo-SP & 1997 \\
\hline
\end{tabular}




\begin{tabular}{|c|c|c|c|}
\hline Classificação & Título & Local & Data \\
\hline P AR78/727.3 F V.1-4 & $\begin{array}{l}\text { Faculdade de Arquitetura e Urbanismo da Universidade de São } \\
\text { Paulo, na Cidade Universitária }\end{array}$ & São Paulo-SP & - \\
\hline P AR78/727.3 F 1962 V.1-3 & $\begin{array}{l}\text { Faculdade de Arquitetura e Urbanismo da Universidade de São } \\
\text { Paulo, na Cidade Universitária }\end{array}$ & São Paulo-SP & 1962 \\
\hline P AR78/727.3 F 1965 & $\begin{array}{l}\text { Faculdade de Arquitetura e Urbanismo da Universidade de São } \\
\text { Paulo, na Cidade Universitária }\end{array}$ & São Paulo-SP & 1965 \\
\hline P AR78/727.3 F 1966 V.1-2 & $\begin{array}{l}\text { Faculdade de Arquitetura e Urbanismo da Universidade de São } \\
\text { Paulo, na Cidade Universitária }\end{array}$ & São Paulo-SP & 1966 \\
\hline P AR78/727.3 F 1967 & $\begin{array}{l}\text { Faculdade de Arquitetura e Urbanismo da Universidade de São } \\
\text { Paulo, na Cidade Universitária }\end{array}$ & São Paulo-SP & 1967 \\
\hline P AR78/727.3 F 1968 V.1-5 & $\begin{array}{l}\text { Faculdade de Arquitetura e Urbanismo da Universidade de São } \\
\text { Paulo, na Cidade Universitária }\end{array}$ & São Paulo-SP & 1968 \\
\hline P AR78/727.3 F 1978 & $\begin{array}{l}\text { Faculdade de Arquitetura e Urbanismo da Universidade de São } \\
\text { Paulo, na Cidade Universitária }\end{array}$ & São Paulo-SP & 1978 \\
\hline P AR78/727.3 FAC & $\begin{array}{l}\text { Faculdade de Arquitetura e Urbanismo da Universidade de São } \\
\text { Paulo, na Cidade Universitária - Reprodução do original em } \\
\text { cópia heliográfica de } 1968\end{array}$ & São Paulo-SP & 1989 \\
\hline P AR78/727.3 FAC 1961 V.1-5 & $\begin{array}{l}\text { Faculdade de Arquitetura e Urbanismo da Universidade de São } \\
\text { Paulo, na Cidade Universitária }\end{array}$ & São Paulo-SP & 1961 \\
\hline P AR78/727.3 FARQ & Faculdade de Arquitetura e Urbanismo & São Paulo-SP & - \\
\hline P AR78/727.3 FAU 1975 & Faculdade de Arquitetura e Urbanismo: Plantas reduzidas & São Paulo-SP & 1975 \\
\hline P AR78/727.3 FAU 1979 & Faculdade de Arquitetura e Urbanismo & São Paulo-SP & 1979 \\
\hline P AR78/727.3 FAU 1991 & Faculdade de Arquitetura e Urbanismo: Rede de informática & São Paulo-SP & 1991 \\
\hline P AR78/727.3 FAU 1994 & Faculdade de Arquitetura e Urbanismo: Atualização & São Paulo-SP & 1994 \\
\hline P AR78/727.3 FAUD & Faculdade de Arquitetura e Urbanismo: Auditório - Reforma & São Paulo-SP & 1983 \\
\hline P AR78/727.3 FAUP & $\begin{array}{l}\text { Faculdade de Arquitetura e Urbanismo: Arquitetura paisagística - } \\
\text { Anteprojeto elaborado pela Profa. Dra. Maria de Assunção R. } \\
\text { Franco }\end{array}$ & São Paulo-SP & 1995 \\
\hline P AR78/727.3 FAZ & $\begin{array}{l}\text { Faculdade de Arquitetura e Urbanismo: Sistema estrutural } \\
\text { provisório para reparo do telhado: plantas, elevações e detalhes }\end{array}$ & São Paulo-SP & 1995 \\
\hline P AR78/727.3 FBI & Faculdade de Arquitetura e Urbanismo: Biblioteca & São Paulo-SP & 1998 \\
\hline P AR78/727.3 FCEX & $\begin{array}{l}\text { Faculdade de Arquitetura e Urbanismo: Canteiro Experimental - } \\
\text { Projeto de Reginaldo Ronconi }\end{array}$ & São Paulo-SP & 1997 \\
\hline P AR78/727.3 FQC & $\begin{array}{l}\text { Faculdade de Arquitetura e Urbanismo: Qualidade das } \\
\text { coberturas planas }\end{array}$ & São Paulo-SP & 1998 \\
\hline P AR78/727.3 FRC & Faculdade de Arquitetura e Urbanismo: Sistema de ar-condicionado & São Paulo-SP & $1974 / 76$ \\
\hline P AR78/727.3 FRT & $\begin{array}{l}\text { Faculdade de Arquitetura e Urbanismo: Concreto da cobertura } \\
\text { "Relatório Técnico da Tecnipol" }\end{array}$ & São Paulo-SP & 1998 \\
\hline P AR78/727.4 ETS & Escola Técnica de Santos, na avenida Nossa Senhora de Fátima & Santos-SP & 1968 \\
\hline P AR78/727.4 SV & $\begin{array}{l}\text { Escola Senai - Vasp, na rua Sebastião Paes com a rua Nhu- } \\
\text { Guaçu, Aeroporto - Ala nova para Departamento de Ensino }\end{array}$ & São Paulo-SP & 1973 \\
\hline P AR78/727.4 VA & $\begin{array}{l}\text { Escola Industrial de Vila Alpina - Senai, na avenida Francisco } \\
\text { Falconi, Vila Prudente }\end{array}$ & São Paulo-SP & 1968 \\
\hline P AR78/727.5 INASA V.1-37 & Instituto Nacional de Saúde Animal - Inasa, em Pedro Leopoldo & Pedro Leopoldo-MG & 1975 \\
\hline P AR78/727.5 LAB & $\begin{array}{l}\text { Laboratório de Recursos Audiovisuais: Reforma do Laboratório } \\
\text { Fotográfico - Instalação hidráulica }\end{array}$ & São Paulo-SP & \\
\hline P AR78/727.6 MAM & $\begin{array}{l}\text { Museu de Arte Moderna de São Paulo - MAM, para os Diários } \\
\text { associados, na rua Sete de Abril, s/n. }\end{array}$ & São Paulo-SP & 1948 \\
\hline P AR78/727.6 MI & Museu Industrial do Governo Federal do Amapá & Macapá-AP & 1971 \\
\hline
\end{tabular}




\begin{tabular}{|c|c|c|c|}
\hline Classificação & Título & Local & Data \\
\hline P AR78/727.9 RP & $\begin{array}{l}\text { Centro Comunitário para a Petrobrás - Refinaria Presidente } \\
\text { Bernardes }\end{array}$ & Cubatão-SP & 1957 \\
\hline P AR78/728.1 AF & $\begin{array}{l}\text { Edifício residencial para o sr. Ary Fachada, na rua Conselheiro } \\
\text { Brotero, 810, Santa Cecília }\end{array}$ & São Paulo-SP & 1953 \\
\hline P AR78/728.1 AM & Edifício residencial Amaralina, na rua Peixoto Gomide, 1559 & São Paulo-SP & 1969 \\
\hline PAR78/728.1 DF & $\begin{array}{l}\text { Edifício residencial para a sra. Dulce Ferreira de Souza Brasil, na } \\
\text { rua João Moura, 942, Pinheiros }\end{array}$ & São Paulo-SP & 1958 \\
\hline PAR78/728.1 EL V.1-2 & $\begin{array}{l}\text { Edifício Louveira para a família Mesquita, na praça Vilaboim, } \\
\text { esquina com a rua Piauí }\end{array}$ & São Paulo-SP & 1948 \\
\hline PAR78/728.1 EU & $\begin{array}{l}\text { Edifício Residencial Europa, para os srs. J. B. V. Artigas, R. Levi, } \\
\text { I. C. Mello, A. S. Paesani e E. K. de Mello, na avenida } 9 \text { de Julho } \\
\text { com a rua Japão }\end{array}$ & São Paulo-SP & 1962 \\
\hline P AR78/728.1 HW & $\begin{array}{l}\text { Edifício residencial para os srs. Hirsch Schor e Waldemar Rays, } \\
\text { na llha Porchat }\end{array}$ & São Vicente-SP & 1950 \\
\hline P AR78/728.1 । & $\begin{array}{l}\text { Edifício residencial para o Instituto de Aposentadoria e } \\
\text { Pensionistas dos Comerciários - lapc, na rua São Vicente de } \\
\text { Paula com Alameda Barros }\end{array}$ & São Paulo-SP & 1946 \\
\hline P AR78/728.1 LJ & Edifício residencial para o sr. Luis Antônio Naves Junqueira & São Paulo-SP & 1967-1978 \\
\hline P AR78/728.1 MA & $\begin{array}{l}\text { Edifício Residencial Califórnia para o sr. Manoel Antonio Mendes } \\
\text { André, na rua Alves Guimarães, } 171 \text {, Jardim América }\end{array}$ & São Paulo-SP & 1970 \\
\hline P AR78/728.1 PG & $\begin{array}{l}\text { Edifício residencial para o sr. João Batista Vilanova Artigas, na } \\
\text { avenida do Flamengo, Jardim Vila Guilhermina }\end{array}$ & Praia Grande-SP & 1963 \\
\hline P AR78/728.1 WM & Edifício residencial para o sr. William Maluf, na rua Maranhão & São Paulo-SP & - \\
\hline P AR78/728.3 AA & $\begin{array}{l}\text { Residência para o sr. Alberto Augusto da Silva Caldas, na rua } \\
\text { Fernando Albuquerque, } 166\end{array}$ & São Paulo - Sp & 1942 \\
\hline P AR78/728.3 ABS & $\begin{array}{l}\text { Residência para o sr. Antonio Barbosa de Souza, na rua } 13 \text { de } \\
\text { Junho com a avenida Afonso Pena }\end{array}$ & Campo Grande-MS & 1971 \\
\hline P AR78/728.3 ACB & $\begin{array}{l}\text { Residência para o sr. Adelino Cândido Baptista, na rua José } \\
\text { Comparato, Cambuci }\end{array}$ & São Paulo-SP & 1958 \\
\hline P AR78/728.3 ACS & Residência Álvaro Corrêa de Sá, na rua Coronel Ducíldio, s/n & Ponta Grossa-PR & 1949 \\
\hline P AR78/728.3 AE & $\begin{array}{l}\text { Residência para a sra. Amelie Elisa Celestine Morin Glover, na } \\
\text { rua Henrique Martins, } 81 \text {, Ibirapuera }\end{array}$ & São Paulo-SP & 1941 \\
\hline P AR78/728.3 AF & $\begin{array}{l}\text { Residência para o sr. Álvaro de Freitas, na rua José Comparato, } \\
\text { s/n., Aclimação }\end{array}$ & São Paulo-SP & 1968 \\
\hline P AR78/728.3 AFC & $\begin{array}{l}\text { Residência para o sr. Antonio Fonseca Castello Branco, na rua } \\
\text { Batatais, } 319\end{array}$ & Barra do Piraí-RJ & 1952 \\
\hline P AR78/728.3 AFF & $\begin{array}{l}\text { Residência para o sr. Antonio Ferreira Filho, no bairro do Sumaré } \\
\text { - Reforma e ampliação }\end{array}$ & São Paulo-SP & 1949 \\
\hline P AR78/728.3 AFP & $\begin{array}{l}\text { Residência para o sr. Alvaro de Freitas Pimentel, na rua Itajubá, } \\
132\end{array}$ & São Paulo-SP & 1943 \\
\hline P AR78/728.3 AG & $\begin{array}{l}\text { Residência para o sr. Alfred Grunther Domschke, na rua D. } \\
\text { Pedro II , 2.040, Campo Belo }\end{array}$ & São Paulo-SP & 1971 \\
\hline P AR78/728.3 AGD V. 1-3 & $\begin{array}{l}\text { Residência para o sr. Alfred Grunther Domschke, na rua } \\
\text { Comendador Elias Zarzur, 2.036, Alto da Boa Vista }\end{array}$ & São Paulo-SP & 1974 \\
\hline P AR78/728.3 AGM & $\begin{array}{l}\text { Residência para o sr. Augusto Gomes de Mattos, na rua } \\
\text { Comandante Ismael Guilherme com a rua Sagres, Ibirapuera }\end{array}$ & São Paulo-SP & 1950 \\
\hline P AR78/728.3 AL & $\begin{array}{l}\text { Residência para o sr. Alcides de Lara Campos, na avenida } \\
\text { Brigadeiro Luís Antônio com a avenida Santo Amaro, 9, Vila Nova } \\
\text { Conceição }\end{array}$ & São Paulo-SP & 1940 \\
\hline P AR78/728.3 AM & $\begin{array}{l}\text { Residência Alfredo Machado Marques, na rua Itajubá, 118, } \\
\text { Pacaembu }\end{array}$ & São Paulo-SP & 1944 \\
\hline
\end{tabular}




\begin{tabular}{|c|c|c|c|}
\hline Classificação & Título & Local & Data \\
\hline P AR78/728.3 AMA & Residência Antenor Mansur Abud & Taubaté-SP & 1969 \\
\hline P AR78/728.3 AMG & $\begin{array}{l}\text { Residência para o sr. Amado Ferreira Mansur Gueiros, na rua } \\
\text { Guaraiúva, 986, Brooklin Paulista }\end{array}$ & São Paulo-SP & 1951 \\
\hline P AR78/728.3 AP & $\begin{array}{l}\text { Residência Aurélio Pereira Lima, na rua Atlântica, 862, Jardim } \\
\text { América }\end{array}$ & São Paulo-SP & 1940 \\
\hline P AR78/728.3 ARI & $\begin{array}{l}\text { Residência Ana Ricaldoni Ponta, na rua Heitor de Morais, 61, } \\
\text { Pacaembu }\end{array}$ & São Paulo-SP & 1942 \\
\hline P AR78/728.3 ARM & $\begin{array}{l}\text { Residência para o sr. Ariosto Martirani, na rua Berlioz, 405, Alto } \\
\text { de Pinheiros }\end{array}$ & São Paulo-SP & 1969 \\
\hline P AR78/728.3 ARP & Residência Ana Ricaldoni Ponta & - & - \\
\hline P AR78/728.3 AS & $\begin{array}{l}\text { Residência para o sr. Álvaro Corrêa de Sá, na alameda Prudente } \\
\text { de Moraes com a rua Saldanha Marinho }\end{array}$ & Curitiba-PR & 1945 \\
\hline P AR78/728.3 ASC & $\begin{array}{l}\text { Residência para o sr. Antônio Salim Curiati, na rua Das Zínias } \\
\text { com a rua dos Plátanos }\end{array}$ & São Paulo-SP & 1978 \\
\hline PAR78/728.3 BE & $\begin{array}{l}\text { Residência para o sr. Bernardo Abramovich, na rua Peixoto } \\
\text { Gomide, } 1.559 \text { - Reforma }\end{array}$ & São Paulo-SP & 1970 \\
\hline P AR78/728.3 BG & $\begin{array}{l}\text { Residência para a sra. Bertha Gift Stirner, na rua Antonio Chagas, } \\
124\end{array}$ & São Paulo-SP & 1940 \\
\hline P AR78/728.3 BL & $\begin{array}{l}\text { Residência para o sr. Benedito Levi, na rua Áustria, 141, esquina } \\
\text { com a rua Inglaterra, Jardim Europa }\end{array}$ & São Paulo-SP & 1944 \\
\hline P AR78/728.3 BR & Residência para a Empresa Tubos Brasilit S/A., em Santo André & Santo André-SP & 1946 \\
\hline P AR78/728.3 CA & $\begin{array}{l}\text { Residência para a Indústria Carbex Química Ltda., na rua José } \\
\text { Freitas Guimarães, Pacaembu }\end{array}$ & São Paulo-SP & 1955 \\
\hline P AR78/728.3 CB & $\begin{array}{l}\text { Residência para o sr. Coralo Bernarde, na rua Dr. Ubaldino do } \\
\text { Amaral }\end{array}$ & Curitiba-PR & 1945 \\
\hline P AR78/728.3 CG & $\begin{array}{l}\text { Residência para o sr. Chaim Goldenstein, na rua Heitor de } \\
\text { Moraes com a rua Wanderley, Perdizes }\end{array}$ & São Paulo-SP & $1952 / 1972$ \\
\hline P AR78/728.3 DM & $\begin{array}{l}\text { Residências para o sr. Duilio Marone, na rua Bastos Pereira, } 529 \\
\text { e 532, Vila Nova Conceição - Duas residências }\end{array}$ & São Paulo-SP & 1940/1941 \\
\hline P AR78/728.3 DMA & $\begin{array}{l}\text { Residência para o sr. Duilio Marone, na avenida Santo Amaro, } \\
\text { 345, esquina com a rua Bastos Pereira, Vila Nova Conceição }\end{array}$ & São Paulo-SP & $1942 / 1943$ \\
\hline P AR78/728.3 DR & $\begin{array}{l}\text { Residência para o sr. David Rosemberg, na rua Morás, 50, } \\
\text { Pinheiros }\end{array}$ & São Paulo-SP & 1950 \\
\hline P AR78/728.3 E & Residência para o dr. Elias e dona Maná, na rua Pedro Bueno & - & 1981 \\
\hline P AR78/728.3 EAP & $\begin{array}{l}\text { Residência para o sr. Ewaldo de Almeida Pinto, na rua Saldanha } \\
\text { Marinho, Brooklin }\end{array}$ & - & 1968 \\
\hline P AR78/728.3 EB & $\begin{array}{l}\text { Residência para a sra. Elza Salvattori Berquó, na rua Paulo } \\
\text { Roberto Paes de Almeida, 51, Chácara Flora - Construção e } \\
\text { ampliação (piscina e casa de hóspedes) }\end{array}$ & São Paulo-SP & $1967 / 1974$ \\
\hline P AR78/728.3 EC & $\begin{array}{l}\text { Residência para o sr. Eduardo Cunha, na rua Fradique Coutinho, } \\
97\end{array}$ & São Paulo-SP & 1941 \\
\hline P AR78/728.3 ECC & $\begin{array}{l}\text { Residência para o sr. Elias Calil Cury, na rua Holanda com a rua } \\
\text { Espanha, Jardim Europa }\end{array}$ & São Paulo-SP & 1969 \\
\hline P AR78/728.3 EL & $\begin{array}{l}\text { Residência para a Sra. Edith Leme lanni, na alameda Jauaperi, } \\
\text { 311, Indianópolis }\end{array}$ & São Paulo-SP & 1960 \\
\hline P AR78/728.3 EN V.1-2 & $\begin{array}{l}\text { Residência para o sr. Edgard A. Niclewicz, na rua Lourenço } \\
\text { Mourão, } 44\end{array}$ & Curitiba-PR & 1978 \\
\hline P AR78/728.3 ER & $\begin{array}{l}\text { Residência para o sr. Elphy Rosenthal, na rua Heitor de Moraes, } \\
\text { 507, Pacaembu }\end{array}$ & São Paulo-SP & 1948 \\
\hline
\end{tabular}




\begin{tabular}{|c|c|c|c|}
\hline Classificação & Título & Local & Data \\
\hline P AR78/728.3 ES & $\begin{array}{l}\text { Residência para o sr. Elly Silva, na rua Roxo Moreira, s/n., Cidade } \\
\text { Universitária }\end{array}$ & Campinas-SP & 1978 \\
\hline P AR78/728.3 FB & $\begin{array}{l}\text { Residência para o sr. Fernando Bebiano Barreto Henriques, na } \\
\text { avenida Rebouças, } 120\end{array}$ & São Paulo-SP & 1940 \\
\hline P AR78/728.3 FBB & $\begin{array}{l}\text { Residência para o sr. Fernando Bebiano Barreto Henriques, na } \\
\text { avenida Santo Amaro, } 23\end{array}$ & São Paulo-SP & 1940 \\
\hline P AR78/728.3 FBBH & $\begin{array}{l}\text { Residência para o sr. Fernando Bebiano Barreto Henriques, na } \\
\text { avenida Santo Amaro, } 357\end{array}$ & São Paulo-SP & 1941 \\
\hline P AR78/728.3 FEB & $\begin{array}{l}\text { Residência para o sr. Fernando Bebiano Barreto Henriques, na } \\
\text { avenida Brigadeiro Luís Antônio, } 4.540\end{array}$ & São Paulo-SP & 1942 \\
\hline P AR78/728.3 FEBB & Residência para o sr. Fernando Bebiano Barreto Henriques & - & - \\
\hline P AR78/728.3 FF & $\begin{array}{l}\text { Residência para o sr. Francisco Franco Teixeira, na rua Tumiaru, } \\
298\end{array}$ & São Paulo-SP & 1941 \\
\hline P AR78/728.3 FG & $\begin{array}{l}\text { Residência para o sr. Febus Gikovate, na rua Ouro Preto, s/n., } \\
\text { Jardim Europa }\end{array}$ & São Paulo-SP & 1949 \\
\hline P AR78/728.3 FH & $\begin{array}{l}\text { Residência para o sr. Fernando Horta, na rua Caramimuan, Alto } \\
\text { de Pinheiros }\end{array}$ & São Paulo-SP & 1973 \\
\hline P AR78/728.3 FL & $\begin{array}{l}\text { Residência para o sr. Frederick Lumley Andrews, na rua Madre } \\
\text { Teodora, } 44\end{array}$ & São Paulo-SP & 1942 \\
\hline P AR78/728.3 FMS & $\begin{array}{l}\text { Residência para o sr. Francisco Matarazzo Sobrinho, na avenida } \\
\text { Lineu de Paula Machado, esquina com a rua Francisco Morato, } \\
\text { Butantã }\end{array}$ & São Paulo-SP & 1949 \\
\hline P AR78/728.3 FR & Residência para o sr. Francisco Ribeiro & - & - \\
\hline P AR78/728.3 GBB & $\begin{array}{l}\text { Residência para o sr. Guilherme Bianchi Benvenuti, na rua } \\
\text { Manoel Maria Tourinho, Pacaembu }\end{array}$ & São Paulo-SP & 1959 \\
\hline P AR78/728.3 GCD & $\begin{array}{l}\text { Residência para o sr. Geraldo Camargo Demétrio, na rua } \\
\text { Barginha, Sumaré }\end{array}$ & São Paulo-SP & 1976 \\
\hline P AR78/728.3 GE & $\begin{array}{l}\text { Residência para o sr. Geraldo D'estefani, na rua José de } \\
\text { Magalhães, } 172\end{array}$ & São Paulo-SP & 1950 \\
\hline P AR78/728.3 GEP & $\begin{array}{l}\text { Residência para o sr. Gilberto e Elisa Périgo, na rua Aparecida } \\
\text { com a rua Durvalina, Vila Mascote }\end{array}$ & São Paulo-SP & 1974 \\
\hline P AR78/728.3 GK & $\begin{array}{l}\text { Residência para o sr. Gilberto Krutman, na rua das Gaivotas, } \\
\text { 180, Moema }\end{array}$ & São Paulo-SP & 1968 \\
\hline P AR78/728.3 GMC & $\begin{array}{l}\text { Residência para o sr. Genulfo Máximo de Carvalho, na rua Clélia, } \\
\text { 237, Vila Romana }\end{array}$ & São Paulo-SP & 1940 \\
\hline P AR78/728.3 GO & $\begin{array}{l}\text { Residência oficial do governador de Goiás, para a Secretaria de } \\
\text { Obras Públicas do Governo de Goiás }\end{array}$ & Goiânia-GO & 1961 \\
\hline P AR78/728.3 GP & Residência para o sr. Giulio Pasquale, na alameda Lorena, 48 & São Paulo-SP & 1939/1942 \\
\hline P AR78/728.3 GS & $\begin{array}{l}\text { Residência para o sr. Gino Saltini, na avenida Brigadeiro Luís } \\
\text { Antônio, } 4.521\end{array}$ & São Paulo-SP & 1944 \\
\hline P AR78/728.3 GVA & $\begin{array}{l}\text { Residência para o sr. Giocondo Vilanova Artigas, na rua Fontana } \\
\text { com a rua da Glória, Lote } 2\end{array}$ & Curitiba-PR & 1950 \\
\hline P AR78/728.3 HA & $\begin{array}{l}\text { Residência Heitor de Almeida, na rua Castro Alves, esquina com } \\
\text { a rua Vergueiro Steidel }\end{array}$ & Santos-SP & 1949 \\
\hline P AR78/728.3 HAT & $\begin{array}{l}\text { Residência para o sr. Hanns Victor Trostli, na rua Guará, 66, } \\
\text { Sumaré }\end{array}$ & São Paulo-SP & $1947-1948$ \\
\hline P AR78/728.3 HH & $\begin{array}{l}\text { Residência Hermann Hugo Scheyer, na rua Antonio das Chagas, } \\
247 \text {, Chácara Santo Antonio }\end{array}$ & São Paulo-SP & 1940 \\
\hline P AR78/728.3 HQ & $\begin{array}{l}\text { Residência Herculano Quadros, na rua Chile, 788, Jardim } \\
\text { América }\end{array}$ & São Paulo-SP & 1941 \\
\hline
\end{tabular}




\begin{tabular}{|c|c|c|c|}
\hline Classificação & Título & Local & Data \\
\hline P AR78/728.3 HS & $\begin{array}{l}\text { Residência Hebert Steffeno, na rua Itaperuna, 36, com a rua } \\
\text { Itaeté }\end{array}$ & São Paulo-SP & 1943 \\
\hline P AR78/728.3 HSC & $\begin{array}{l}\text { Residência para o sr. Hirsch Schor, na rua Caiuby, 329, Perdizes } \\
\text { - Reforma }\end{array}$ & São Paulo-SP & - \\
\hline P AR78/728.3 HV & $\begin{array}{l}\text { Residência para o sr. Henrique Villaboim Filho, na avenida dos } \\
\text { Amariles c/ Viela, Cidade Jardim }\end{array}$ & São Paulo-SP & 1966 \\
\hline P AR78/728.3 HVT & Residência para o sr. Hanns Victor Trostli, Cachoeirinha & Sào Paulo-SP & 1958 \\
\hline P AR78/728.3 IAV & $\begin{array}{l}\text { Residência para o sr. Ivo Antonio Viterito, na rua José Comparato, } \\
\text { 106, Aclimação }\end{array}$ & São Paulo-SP & 1962 \\
\hline P AR78/728.3 IP & $\begin{array}{l}\text { Residência para o sr. Ïsaac Pechelman, na rua Ferdinando } \\
\text { Laboriam, 124, Pacaembu }\end{array}$ & São Paulo-SP & 1954 \\
\hline P AR78/728.3 IV & $\begin{array}{l}\text { Residência para o sr. Inocêncio Vilanova Jr., na rua Prudente de } \\
\text { Morais, s/n. }\end{array}$ & Curitiba-PR & 1945 \\
\hline P AR78/728.3 IV & $\begin{array}{l}\text { Residência Inocêncio Vilanova Jr., na rua Prudente de Morais, } \\
\text { s/n. }\end{array}$ & Curitiba-PR & 1945 \\
\hline P AR78/728.3 JAR & $\begin{array}{l}\text { Residência para João Átila Rocha, na rua Fontana com a rua } \\
\text { Glória, Lote } 3\end{array}$ & Curitiba-PR & 1950 \\
\hline P AR78/728.3 JB & $\begin{array}{l}\text { Residência para o sr. José Mario Taques Bittencourt, na rua } \\
\text { Votuporanga, no bairro do Sumaré }\end{array}$ & São Paulo-SP & 1959 \\
\hline P AR78/728.3 JBB & Residência para o dr. João Beline Burza & Ouro Fino & 1979 \\
\hline P AR78/728.3 JBI & $\begin{array}{l}\text { Residência para o sr. José Mario Taques Bittencourt - Bairro do } \\
\text { Sumaré, na rua Votuporanga, } 275\end{array}$ & São Paulo-SP & 1949 \\
\hline P AR78/728.3 JCA & $\begin{array}{l}\text { Residência para o sr. José Carlos Amaral de Oliveira, na rua das } \\
\text { Magnólias, 480, Cidade Jardim }\end{array}$ & São Paulo-SP & 1941 \\
\hline P AR78/728.3 JCC & $\begin{array}{l}\text { Residência para o sr. João Carlos Celidônio Gomes dos Reis, na } \\
\text { avenida Waldemar Ferreira, 199, Butantã }\end{array}$ & São Paulo-SP & 1975 \\
\hline P AR78/728.3 JCP & $\begin{array}{l}\text { Residência para o sr. José Coelho Pamplona, na rua Capitão-Mor } \\
\text { Gonçalo Monteiro, } 23 \text { a } 55 \text { - Vila de } 12 \text { residências, em } 4 \text { Grupos } \\
\text { de } 3 \text { casas }\end{array}$ & São Paulo-SP & 1942 \\
\hline P AR78/728.3 JD & $\begin{array}{l}\text { Residência para o sr. José David Vicente, no bairro Nova } \\
\text { Campinas }\end{array}$ & Campinas-SP & 1959 \\
\hline P AR78/728.3 JEA & Residência para o sr. Jorge Edney Atalla, na rua 7 de Setembro & Jaú-SP & 1971 \\
\hline P AR78/728.3 JF & Residência José Ferreira Fernandes, Alto de Pinheiros & São Paulo-SP & 1957 \\
\hline P AR78/728.3 JFS & $\begin{array}{l}\text { Residência para o sr. José Franco de Souza, na avenida 1, } \\
\text { esquina com a rua 3, Lote 1, Quadra H, Jardim Vitória Régia }\end{array}$ & São Paulo-SP & - \\
\hline P AR78/728.3 JJ & $\begin{array}{l}\text { Residência para o sr. Juvenal Juvêncio, na rua Pirapó, 181, } \\
\text { Jardim Guedala }\end{array}$ & São Paulo-SP & 1972 \\
\hline P AR78/728.3 JK & $\begin{array}{l}\text { Residência para sra. Jeny Klury, na avenida Ruy Barbosa, Vila } \\
\text { Itaipu }\end{array}$ & São Vicente-SP & 1948 \\
\hline P AR78/728.3 JL & Residência para o sr. João Luiz Bettega, na rua da Paz, 479 & Curitiba-PR & 1953 \\
\hline P AR78/728.3 JLM & $\begin{array}{l}\text { Residência para o sr. José Luiz Magnani, na rua São Ludgero, } \\
\text { Santo Amaro }\end{array}$ & São Paulo-SP & 1981 \\
\hline P AR78/728.3 JM & Residência para o sr. José Mehry, na avenida João Gualberto & São Paulo-SP & 1942 \\
\hline P AR78/728.3 JMB V.1-2 & $\begin{array}{l}\text { Residência para o sr. José Taques Bittencourt e Lucia } \\
\text { Bittencourt, na rua Votuporanga, } 268 \text {, Sumaré }\end{array}$ & São Paulo-SP & 1981 \\
\hline P AR78/728.3 JMO & Residência José Morganti, na rua Salvador Correa, 7, Aclimação & São Paulo-SP & 1938 \\
\hline P AR78/728.3 JOM & $\begin{array}{l}\text { Residência na rua João Moura, } 100 \text { - Quarto de empregada, } \\
\text { banheiro e garagem }\end{array}$ & São Paulo-SP & \\
\hline P AR78/728.3 JOMO & $\begin{array}{l}\text { Residência para o sr. João Molina, na avenida } 5 \text { com a avenida } \\
\text { Jundiaí }\end{array}$ & Jundiaí-SP & 1959 \\
\hline
\end{tabular}




\begin{tabular}{|c|c|c|c|}
\hline Classificação & Título & Local & Data \\
\hline P AR78/728.3 JP & $\begin{array}{l}\text { Conjunto de } 4 \text { casas para Eusébio e Jaime Porchal, na rua } \\
\text { Sampaio Vidal, 550, Jardim Paulista }\end{array}$ & São Paulo-SP & 1944 \\
\hline P AR78/728.3 JVA & $\begin{array}{l}\text { Residência para Joel Vilanova Artigas, na rua Fontana, } 220 \text { com } \\
\text { a rua da Glória, 220, Lote } 1\end{array}$ & Curitiba-PR & 1950 \\
\hline P AR78/728.3 JVN & $\begin{array}{l}\text { Residência para o sr. José Vieitas Neto, na avenida Córrego do } \\
\text { Sapateiro com a rua Dr. Esdras }\end{array}$ & São Paulo-SP & 1968 \\
\hline P AR78/728.3 KE & Residência para o sr. Keiserman - Reforma & - & - \\
\hline P AR78/728.3 LA & $\begin{array}{l}\text { Residência para o sr. Luiz Antonio Leite Ribeiro, na rua Turquia, } \\
42\end{array}$ & São Paulo-SP & 1941 \\
\hline P AR78/728.3 LAL & $\begin{array}{l}\text { Residência para o sr. Luiz Antonio Leite Ribeiro, na rua Heitor de } \\
\text { Moraes, 257, Pacaembu }\end{array}$ & São Paulo-SP & 1943 \\
\hline P AR78/728.3 LALR & $\begin{array}{l}\text { Residência para o sr. Luiz Antonio Leite Ribeiro, na rua Bento de } \\
\text { Andrade, } 516 \text { e } 526 \text {, Ibirapuera ( } 2 \text { casas) }\end{array}$ & São Paulo-SP & 1942 \\
\hline P AR78/728.3 LAT & $\begin{array}{l}\text { Residência para o sr. Luiz Arouche de Toledo, na rua Tavares } \\
\text { Cabral, } 133\end{array}$ & São Paulo-SP & 1942 \\
\hline P AR78/728.3 LAU & $\begin{array}{l}\text { Residência para o sr. Luiz Aulicino, na avenida Brigadeiro Luís } \\
\text { Antonio, } 4.469\end{array}$ & São Paulo-SP & 1941 \\
\hline P AR78/728.3 LCU & $\begin{array}{l}\text { Residência para o sr. Luiz Carlos Uchoa Junqueira, na avenida } \\
\text { Central, } 223 \text { esq. avenida Portugal - Brooklin Novo }\end{array}$ & São Paulo-SP & 1944 \\
\hline P AR78/728.3 LG & $\begin{array}{l}\text { Residência para o sr. Luiz Gonzaga Leme Monteiro, na rua Das } \\
\text { Magnólias com a rua Claudina Silva }\end{array}$ & São Paulo-SP & 1941 \\
\hline P AR78/728.3 LL & $\begin{array}{l}\text { Residência para a Sra. Lúcia Lara Campos, na rua Alaska, } 66, \\
\text { Jardim América - Reforma e ampliação }\end{array}$ & São Paulo-SP & $1942-44$ \\
\hline P AR78/728.3 LLA & Residência para a sra. Lúcia Lara Campos, na rua Antônio Bento & - & - \\
\hline P AR78/728.3 LLI & $\begin{array}{l}\text { Residência para o sr. Luiz Lúcio Izzo, na Avenida Morumbi com a } \\
\text { rua São Braulio, Jardim Leonor }\end{array}$ & São Paulo-SP & 1974 \\
\hline P AR78/728.3 LM & Residência Leão Machado & - & 1948 \\
\hline P AR78/728.3 LN & $\begin{array}{l}\text { Residência para o sr. Léo Pereira Lemos Nogueira, na rua Ismael } \\
\text { Guilherme, Lote 7, Quadra K, Jardim Luzitânia }\end{array}$ & São Paulo-SP & 1959 \\
\hline P AR78/728.3 LRM & $\begin{array}{l}\text { Residências para o sr. Leo Ribeiro de Moraes, na rua Marcelina } \\
\text { com as ruas Duílio e Camilo }\end{array}$ & São Paulo-SP & 1945 \\
\hline P AR78/728.3 M & Residência M. C. & - & 1967 \\
\hline P AR78/728.3 MA & Residência Maria Amélia Jank, na rua Morgado de Mateus, 127 & São Paulo-SP & 1942 \\
\hline P AR78/728.3 MAM & $\begin{array}{l}\text { Residência para o sr. Manoel Antonio Mendes André, na rua Cel. } \\
\text { Artur de Godói, 203, Vila Mariana }\end{array}$ & São Paulo-SP & 1966 \\
\hline P AR78/728.3 MAMA & $\begin{array}{l}\text { Residência para o sr. Manoel Antonio Mendes André, na rua Cel. } \\
\text { Artur de Godói, } 185 \text {, Vila Mariana }\end{array}$ & São Paulo-SP & 1952 \\
\hline P AR78/728.3 MAN & Residência para o sr. Manoel Antonio Mendes André & - & 1951 \\
\hline P AR78/728.3 MANA & $\begin{array}{l}\text { Residência para o sr. Manoel Antonio Mendes André, na rua } \\
\text { Alves Guimarães }\end{array}$ & São Paulo-SP & 1948 \\
\hline P AR78/728.3 MC & Residência para o sr. Milton da Costa & São Paulo-SP & 1961 \\
\hline P AR78/728.3 MD & Residência Max Dreifuss, na rua Antonio das Chagas, 280 & São Paulo-SP & 1940 \\
\hline P AR78/728.3 MF & $\begin{array}{l}\text { Residência para o sr. Moacyr de Freitas Amorim, na avenida } \\
\text { Prof. Afonso Bovero, } 218\end{array}$ & São Paulo-SP & 1944 \\
\hline P AR78/728.3 MM & $\begin{array}{l}\text { Residência para o sr. Manuel Montiel, em San Isidoro, Lima, } \\
\text { Peru }\end{array}$ & Lima-Peru & 1974 \\
\hline P AR78/728.3 MMA & Residência para o sr. Manuel Antonio Mendes André & - & - \\
\hline P AR78/728.3 MRB & $\begin{array}{l}\text { Residências para a sra. Maria Risoleta Bueno Pamplona, na rua } \\
\text { Assis - Grupo de quatro residências, } 50 / 5\end{array}$ & São Paulo-SP & 1942 \\
\hline
\end{tabular}




\begin{tabular}{|c|c|c|c|}
\hline Classificação & Título & Local & Data \\
\hline P AR78/728.3 MRM & Residência para o sr. Milton Ribeiro de Menezes, na rua Ceará & Londrina-PR & 1950 \\
\hline P AR78/728.3 N & $\begin{array}{l}\text { Residência para o sr. Eli Daniel Nassi, na rua Piracicaba, } 808, \\
\text { Brooklin Paulista }\end{array}$ & São Paulo-SP & 1948 \\
\hline P AR78/728.3 NB & $\begin{array}{l}\text { Residência para o sr. Newton Bernardes, na rua Pasqual Vita, } \\
\text { Alto de Pinheiros }\end{array}$ & São Paulo-SP & 1969 \\
\hline P AR78/728.3 NM & $\begin{array}{l}\text { Residência para a sra. Noemia Marone, na rua General Rondon, } \\
\text { 118, Campos Elíseos - Reforma }\end{array}$ & São Paulo-SP & 1937 \\
\hline P AR78/728.3 NP & $\begin{array}{l}\text { Residência para o sr. Nelson Pereira da Costa, na rua Noruega, } \\
15\end{array}$ & São Paulo-SP & 1939 \\
\hline P AR78/728.3 NS & $\begin{array}{l}\text { Residência para o sr. Nicolau Scarpa Júnior, na rua Haguassu, } \\
\text { 91, Pacaembu (Atual rua Manuel Maria Tourinho) }\end{array}$ & São Paulo-SP & 1940/44 \\
\hline P AR78/728.3 NTO & $\begin{array}{l}\text { Residência para o sr. Nelson Tabajara de Oliveira, na rua das } \\
\text { Magnólias, } 490\end{array}$ & São Paulo-SP & 1941 \\
\hline P AR78/728.3 OA & $\begin{array}{l}\text { Residência para o sr. Ottoni de Arruda Castanho, na rua Cotoxó, } \\
531 \text {, com a rua Desembargador do Vale, Pompéia }\end{array}$ & São Paulo-SP & 1939 \\
\hline P AR78/728.3 OB & $\begin{array}{l}\text { Residência para a sra. Olga e sr. Sebastião Baeta, na rua Gaspar } \\
\text { Moreira, Butantã }\end{array}$ & São Paulo-SP & 1957 \\
\hline P AR78/728.3 OH & $\begin{array}{l}\text { Residência para o sr. Orlando Holzmann, na rua Augusto Ribas } \\
\text { com a rua Padre Ildefonso }\end{array}$ & Ponta Grossa-PR & 1945 \\
\hline P AR78/728.3 OM & $\begin{array}{l}\text { Residência para o sr. Orlando Martinelli, na rua José Comparato, } \\
\text { s/n, Cambuci }\end{array}$ & São Paulo-SP & 1958 \\
\hline P AR78/728.3 OV & $\begin{array}{l}\text { Residência para o sr. Oduvaldo Vianna, na avenida Dr. Arnaldo, } \\
\text { Quadra 2, Lote 26, Sumaré }\end{array}$ & São Paulo-SP & 1951 \\
\hline P AR78/728.3 P & Residência na avenida Pacaembu & São Paulo-SP & 1943 \\
\hline P AR78/728.3 PE & $\begin{array}{l}\text { Residência para o sr. Paulo Emílio Gomes dos Reis, na rua } \\
\text { Almirante Pereira Guimarães, 378, Pacaembu }\end{array}$ & São Paulo-SP & 1951 \\
\hline P AR78/728.3 PGG & $\begin{array}{l}\text { Residência Paulo Garcia Guimarães, na rua Honduras, } 124 \text { - } \\
\text { Reforma }\end{array}$ & São Paulo-SP & 1943 \\
\hline P AR78/728.3 PS & $\begin{array}{l}\text { Residência para o sr. Paulo Seixas Queiroz, na rua da Mata, 70, } \\
\text { Itaim Bibi }\end{array}$ & São Paulo-SP & 1967 \\
\hline P AR78/728.3 RBP & $\begin{array}{l}\text { Residência para o sr. Rio Branco Paranhos, na rua Heitor de } \\
\text { Morais, } 120 \text {, Pacaembu }\end{array}$ & São Paulo-SP & 1943 \\
\hline P AR78/728.3 RDM & $\begin{array}{l}\text { Residência Rubens de Mendonça, na rua Guaçu, 176, Sumaré } \\
\text { (Casa dos Triângulos) }\end{array}$ & São Paulo-SP & 1958 \\
\hline P AR78/728.3 RF & $\begin{array}{l}\text { Residência do sr. Rui Franco, na rua Martinho, esq. com a rua } \\
\text { Victorino Carmilo - Reforma }\end{array}$ & São Paulo-SP & 1961 \\
\hline P AR78/728.3 RHA & $\begin{array}{l}\text { Residência Henrique Arouche de Toledo, na rua Itapicuru, 509, } \\
\text { Perdizes }\end{array}$ & São Paulo-SP & 1938 \\
\hline P AR78/728.3 RIM & $\begin{array}{l}\text { Residência para Rivadávia Mendonça, na rua Itaguassu (Atual r. } \\
\text { Manoel Maria Tourinho), Pacaembu }\end{array}$ & São Paulo-SP & 1944 \\
\hline P AR78/728.3 RL & Residência para o sr. Roberto Lacaze, na avenida Sumaré, 460 & São Paulo-SP & 1941 \\
\hline P AR78/728.3 RM & $\begin{array}{l}\text { Residência para o sr. Rui Martins Ferreira, na rua Cons. Torres } \\
\text { Homem, 441, Jardim Paulista }\end{array}$ & São Paulo-SP & 1940 \\
\hline P AR78/728.3 RQA & Residência para o sr. Quirino de Andrade, na alameda Lorena & São Paulo-SP & 1938 \\
\hline P AR78/728.3 RR & $\begin{array}{l}\text { Residência para Ricardo Ricaldoni (1), na rua Itaguassu, Lote } 44 \text {, } \\
\text { Pacaembu (Atual rua Manoel Maria Tourinho) }\end{array}$ & São Paulo-SP & 1945 \\
\hline P AR78/728.3 RRA & $\begin{array}{l}\text { Residência para Ricardo Ricaldoni (2), na rua Itaguassu, Lote } 39 \text {, } \\
\text { Pacaembu }\end{array}$ & São Paulo-SP & 1945 \\
\hline P AR78/728.3 RS & $\begin{array}{l}\text { Residência para o sr. Roberto Salmeron, na rua Rui Barbosa com } \\
\text { a esq. avenida Almirante Barroso, Campo Belo }\end{array}$ & São Paulo-SP & 1949 \\
\hline
\end{tabular}




\begin{tabular}{|c|c|c|c|}
\hline Classificação & Título & Local & Data \\
\hline P AR78/728.3 RSF & $\begin{array}{l}\text { Residência para o sr. Renato S. Faucz, na rua Marechal Hermes } \\
\mathrm{s} / \mathrm{n} \text {. }\end{array}$ & Curitiba-PR & 1975 \\
\hline P AR78/728.3 SK & $\begin{array}{l}\text { Residência para o sr. Suher Krasner, na praça Charles Miller com } \\
\text { a rua Heitor de Moraes, Pacaembu - Reforma interna }\end{array}$ & São Paulo-SP & 1948 \\
\hline P AR78/728.3 TB & $\begin{array}{l}\text { Residência Antônio Luis Teixeira Barros, na rua Turquia, } 468 \text {, } \\
\text { Jardim Europa }\end{array}$ & São Paulo-SP & 1946 \\
\hline P AR78/728.3 TP & $\begin{array}{l}\text { Residência Telmo Fernades de Aragão Porto, na rua Dr. Costa } \\
\text { Júnior, 230, Perdizes }\end{array}$ & São Paulo-SP & 1968 \\
\hline P AR78/728.3 TR & $\begin{array}{l}\text { Residência para o sr. Tito Ribeiro de Almeida, na rua Marechal } \\
\text { Bittencourt com a rua Maestro Chiaffarelli, Jardim Paulista }\end{array}$ & São Paulo-SP & 1946 \\
\hline P AR78/728.3 VA & $\begin{array}{l}\text { Residência para o sr. João B. V. Artigas, na rua Piracicaba com a } \\
\text { rua Barão de Jaceguai, } 1.149 \text { (casinha) }\end{array}$ & São Paulo-SP & 1942 \\
\hline P AR78/728.3 VAR & $\begin{array}{l}\text { Residência para o sr. João B. V. Artigas, na rua Barão de } \\
\text { Jaceguai, } 1.151 \text { (2. casa do arquiteto) }\end{array}$ & São Paulo-SP & 1949 \\
\hline P AR78/728.3 VBR & Residência para o sr. Vitor Brecheret, na rua Alemanha, 115 & Sào Paulo-SP & 1943 \\
\hline P AR78/728.3 WC & $\begin{array}{l}\text { Residência para o sr. Waldemar Cordeiro, na rua Pombal, } 415 \text {, } \\
\text { Sumaré }\end{array}$ & São Paulo-SP & 1970 \\
\hline P AR78/728.5 HJ & Hotel e Centro de Convenções para a Prefeitura Municipal de Jaú & Jaú-SP & 1978 \\
\hline P AR78/728.5 HM & Hotel Monteverde & Monte Verde-MG & 1977 \\
\hline P AR78/728.52 BJ V.1 e 2 & Balneário-1, nas avenidas do Café e João Ferraz Neto & Jaú-SP & 1975 \\
\hline P AR78/728.52 BJA V.1 - 2B & Balneário-2, na rua 24 de Maio com a rua Jesuíno dos Santos & Jaú-SP & 1975 \\
\hline P AR78/728.55 CM & $\begin{array}{l}\text { Colônia de Férias do Sindicato dos Trabalhadores nas indústrias } \\
\text { Metalúrgica, Mecânica e de Material Elétrico de São Paulo, na } \\
\text { avenida Dom Pedro II, Vila Califórnia }\end{array}$ & Praia Grande-SP & 1963 \\
\hline P AR78/728.55 CVR V.1-12 & $\begin{array}{l}\text { Colônia de Férias do Sindicato dos Condutores de Veículos } \\
\text { Rodoviários de São Paulo, na avenida dos Sindicatos, Vila Mirim }\end{array}$ & Praia Grande-SP & 1973/1983 \\
\hline P AR78/728.55 CVR V.1-12 & $\begin{array}{l}\text { Colônia de Férias do Sindicato dos Condutores de Veículos } \\
\text { Rodoviários de São Paulo, na avenida dos Sindicatos, Vila Mirim }\end{array}$ & Praia Grande-SP & $1973 / 1983$ \\
\hline P AR78/728.55 CVR V.1-12 & $\begin{array}{l}\text { Colônia de Férias do Sindicato dos Condutores de Veículos } \\
\text { Rodoviários de São Paulo, na avenida dos Sindicatos, Vila Mirim }\end{array}$ & Praia Grande-SP & 1973/1983 \\
\hline P AR78/728.55 T V.1-10 & $\begin{array}{l}\text { Colônia de Férias para o Sindicato dos Trabalhadores nas } \\
\text { Indústrias de Fiação e Tecelagem de São Paulo, na Praia Grande } \\
\text { (Vila Mirim) }\end{array}$ & Praia Grande-SP & $\begin{array}{l}1969 / 1987 / 1 \\
991\end{array}$ \\
\hline P AR78/728.55 UNSP V.1-7 & $\begin{array}{l}\text { Colônia de Férias da União Nacional dos Servidores Públicos } \\
\text { (Unsp), Praia Grande }\end{array}$ & Praia Grande-SP & 1975 \\
\hline P AR78/728.67 LJ & Casa de fazenda para o sr. Luiz Antonio N. Junqueira & - & 1973 \\
\hline P AR78/728.67 MA & Sede de fazenda para o sr. Manuel Antonio Mendes André & São Paulo-SP & 1956 \\
\hline P AR78/728.7 EB & $\begin{array}{l}\text { Casa de praia para a Sra. Elza Bernardi, na rua 1, Quadra 4, Lote } \\
6 \text {, Jardim Star }\end{array}$ & Peruíbe-SP & 1974 \\
\hline P AR78/728.7 GA & $\begin{array}{l}\text { Casa de praia para o sr. Giocondo Vilanova Artigas, na avenida } \\
\text { Manuel Ribas, Quadra 5, Lote 2, Vila de Caiobá }\end{array}$ & Caiobá-PR & 1961 \\
\hline P AR78/728.7 JA & $\begin{array}{l}\text { Casa de praia para o sr. Joel Vilanova Artigas, na Quadra 1, Lote } \\
\text { 3, Vila Caiobá }\end{array}$ & Caiobá-PR & - \\
\hline P AR78/728.7 JR V.1-2 & $\begin{array}{l}\text { Casa de praia para a sra. Júlia Romano Corrêa, na praia do } \\
\text { Juqueí }\end{array}$ & São Sebastião-SP & 1980 \\
\hline P AR78/728.7 MN & $\begin{array}{l}\text { Casa de praia para Márcia Nemes Yano, na rua 5, Quadra 10, } \\
\text { Lote 5, Estância Balneária Belmira Novaes }\end{array}$ & Peruíbe-SP & 1977 \\
\hline P AR78/728.7 MS & Casa de campo para o sr. Marcílio Schiavon & - & 1972 \\
\hline
\end{tabular}

